\title{
Era uma vez... uma análise*
}

\author{
Sandra Maria da Mata Azerêdo** \\ Em homenagem a Camille Claudel, \\ que fez a escultura Les Bavardes, que \\ traduzimos como As Faladeiras.
}

O ensaio que se segue narra uma experiência de análise vivida há mais de 15 anos. Foi achado por mero acaso, quando me mudei para meu próprio apartamento, e estava arrumando coisas do baú. Tinha me esquecido que um dia o havia escrito $e$ senti um enorme alívio e uma grande alegria ao lê-lo. Decidi publicá-lo porque o vejo como um testemunho de que é possível sair de uma situação de violência de gênero, isto é, a violência que quase todas as mulheres $e$ outras pessoas excluídas sofrem em algum momento de sua vida pelo simples fato de serem mulheres ou por se acharem numa situação de exclusão. Conforme escreve Hannah Arendt,

a violência, distinguindo-se do poder, é muda; a violência tem início onde termina a fala. Quando usadas com o propósito de lutar, as palavras perdem sua qualidade de fala; transformam-se em clichês. ${ }^{1}$

Na violência contra as mulheres há uma especificidade, que Maria Filomena Gregori chama de "o buraco negro da violência

\footnotetext{
* Recebido para publicação em fevereiro de 2003.

*** Psicóloga, professora adjunta da Universidade Federal de Minas Gerais. Azeredo@fafich.ufmg.br

1 Arendt, Hanna. A Dignidade da Política: Ensaios e Conferências. Rio de Janeiro, Relume Dumará, 1993, p.40.
}

cadernos pagu (20) 2003: pp.205-216. 
contra a mulher". Trata-se de "situações em que a mulher se produz - não é apenas produzida - como não-sujeito" , colocando-se no lugar de vítima, passiva. Gregori aponta também para a complexa relação que a mulher - vítima - tem com o sofrimento, como se fosse algo que é cultivado para dar sentido à sua vida. A epígrafe de Paulo Mendes Campos que escolhi quando escrevi o texto original pode ser lida como falando deste lugar de vítima, que, de certa forma, deixa a dor transbordar e corre o risco de se afogar nela. No caso narrado aqui, eu estava procurando análise justamente para sair deste lugar.

Acredito que, neste caso, foi possível sair dessa situação, sobretudo, porque eu estava aberta a dois tipos de escuta - a escuta da linguagem do inconsciente, que é a linguagem da dimensão invisível da vida - dos sonhos e do dito nas entrelinhas - e a escuta da linguagem dos feminismos, que representa para mim a dimensão política da vida. Atualmente, como parte de uma pesquisa sobre o sentido da violência, estou coordenando um grupo de mulheres na Delegacia de Crimes contra a Mulher, em Belo Horizonte, procurando abrir para as mulheres esses dois tipos de escuta de modo a fazer emergirem demandas sociais que lhes possibilitem sair dessas situações usando seus próprio recursos.

A publicação deste ensaio pretende também mostrar como qualquer situação de relação de poder, onde há hierarquia, seja a de analista e paciente, como no caso narrado, seja a de professor/a e aluno/a, ou a de patroa/ão e empregada/o, a pessoa no lado mais forte da relação pode tentar impor sua visão de mundo à pessoa do outro lado, abandonando o campo da fala $e$ do discurso, que é o campo onde se dão as relações de poder e resistência, e passando ao campo da violência, onde o ato $e$ as palavras são usados para reforçar estereótipos. Neste caso, o analista passou ao ato, ao se aproximar da paciente para

2 Gregori, Maria Filomena, Cenas e Queixas: Um estudo sobre mulheres, relaçóes violentas e a prática feminista. Rio de Janeiro/São Paulo, Paz e Terra/ANPOCS, 1992, p.184. 
comparar o tamanho de suas mãos, o que a assustou e ao mesmo tempo a encantou. Mais tarde, ela veio a saber que numa situação de discussão com uma outra mulher, este mesmo analista acabou por mostrar o pênis a ela, argumentando que "isso" ela não tinha.

$\mathrm{O}$ ensaio necessitou apenas algumas pequenas revisões, entre elas, manter o anonimato do analista. Mais do que denunciar o analista, o que seria impossível agora, tendo já se passado tanto tempo, o que se pretende é contribuir para o debate sobre a questão da ética nos atendimentos psicológicos. Esta ética parece estar sendo comprometida em uma série de casos atendidos por profissionais psi - homens e mulheres. Desde Freud, tem sido uma prática comum entre psicanalistas $e$ psicoterapeutas publicar casos clínicos, usando relatos de sessões com pacientes. Acredito que seja o momento desta prática se estender ao grupo de pacientes, de modo que possamos ter uma visão mais abrangente do que ocorre nos atendimentos realizados com base nos estudos de Psicologia e Psicanálise. Não se trata de iniciar uma caça às bruxas, mas abrirmos a discussão sobre a ética desses atendimentos.

A dor também tem o seu feitiço, e este se vira contra o enfeitiçado. Por isso Alice, depois de ter chorado um lago, pensava: "Agora serei castigada, afogando-me em minhas próprias lágrimas". Conclusão: a própria dor deve ter a sua medida: É feio, é imodesto, é vão, é perigoso ultrapassar a fronteira de nossa dor, Maria da Graça.

Paulo Mendes Campos

"Eu vou te comer". Ele havia dito no primeiro encontro, quer dizer, na primeira entrevista. "Você é um prato cheio". Na verdade, ele havia falado apenas esta última frase, mas o que ela havia escutado, mesmo sem o saber, era a primeira. Deve ter sido por isto que ela ficara tão seduzida por ter sido chamada de "prato cheio". Psicóloga que era, esta frase dita por um psicanalista na primeira entrevista não poderia ter sido recebida tão sem crítica. Só podia estar se repetindo ali a história do Lobo e da 
Chapeuzinho. Afinal de contas, ela estava procurando análise justamente porque havia esta Chapeuzinho que insistia em aparecer nas situações menos esperadas, retirando de cena a mulher experiente. E não deu outra. A Chapeuzinho apareceu assim que a mulher ouviu o homem dizer que ela era um "prato cheio".

A história, como de toda Chapeuzinho, foi se desenrolando às mil maravilhas - enquanto o Lobo estava fantasiado de analista e a mulher experiente estava transformada em Chapeuzinho. No início da sessão, ele costumava oferecer um "ursinho" a ela, em forma de almofada, que ela uma vez, brincando, chamou de "meu ursinho". Aliás, eles brincavam muito. E riam demais. Ela achava isto divertidíssimo e inteiramente novo. Sempre dizia a todo mundo que o que mais gostava em seu analista era seu senso de humor. Outra coisa de que ela gostava era que ele parecia não ter medo das palavras. Falava um monte de palavrões, com a maior naturalidade. Ela nem se importava muito que ele cometesse alguns erros de português de vez em quando (falava "sege" ao invés de "seja" e "clitóris" ao invés de "clítoris"). Como professora, isto a incomodava, mas estava tão encantada com ele, que tudo passava.

Parecia também que ele tinha uma teoria pronta sobre ela, e tudo tinha que se encaixar na tal teoria. A teoria, que ele um dia contou a ela, era que ela "tinha sido estruturada pelo pai e não pela mãe". Havia uma rejeição básica, uma falta que vinha da mãe dela, e apenas o pai a tinha estruturado. Daí ela ser feminista, e não ser feminina. Daí ela não saber ocupar o lugar de mulher. Daí ela não conseguir uma relação com um homem de verdade. Isto era uma coisa que sempre a preocupara na análise. Ela era feminista sim, e estava questionando justamente o lugar tradicional da mulher, do feminino. Será que ele tinha abertura para questionar as visões tradicionais do que era ser mulher?

Mas ele era mesmo um homem com quem ela estava se encontrando duas vezes por semana (ela havia pedido mais uma sessão) e uma noite aconteceu o sonho. Um grupo de 
adolescentes colocou nela um sapato preto de salto alto, penteou seus cabelos, e ela foi, linda, se encontrar com ele na casa em que ele morava. Ele lhe fez um galanteio, que ela não ouviu bem, e disse: "O que eu queria mesmo era te convidar para jantar". Se abraçaram e se olharam bem no fundo dos olhos, sabendo que isto era impossível, e que ela poderia ficar tranqüila, que ali ela não corria risco. Quando ouviu o sonho, ele confirmou que ela ali não corria o risco de repetir relações incestuosas, e deu o maior reforço nos adolescentes que a estavam ensinando a ser mulher.

Uma vez ela colocou as sandálias mais lindas que tinha pra ir à análise e foi despencando ladeira abaixo, porque as solas eram muito lisas. Riram muito disto - de ela despencar. Ela não tivera coragem de dizer que colocara as sandálias para ele notar. Mais tarde, ele sugeriu que ela havia sido punida porque calçara "aquelas sandálias franciscanas", e não o sapato de salto alto que os adolescentes a tinham dado. Uma outra vez, ele perguntara se ela estava deixando crescer as unhas [ela não estava], sugerindo que ela estava se tornando mais mulher.

Quando um dia ela comunicou que ia faltar à análise para assistir à conferência de um homem no qual estava interessada, ele sugeriu que ela estava identificando o homem com ele. Ela concordou, dizendo que com aquele homem podia fazer coisas que com ele não podia. Depois da conferência ela comentou que o homem só se interessava pelas coisas que estavam em sua cabeça, e nem notava que ela tinha um corpo, perguntando se devia tirar a roupa para ele a notar. Ele respondeu que ela sabia muito bem que não era por aí.

Certa vez ela sonhou que ele estava na cadeira de rodas, ensinando sua família a cuidar dela. Ela tinha se sentido muito protegida e repetia para o pai que estava apaixonada pelo analista. O sonho foi interrompido pelo barulho de moto que passava na rua e, quando ela voltou a dormir, sonhou que estava indo para a análise para contar a ele o sonho em que estava apaixonada, mas teve que lidar com uma porção de crianças que a atropelavam e acabou chegando 5 minutos antes de terminar 
sua hora. No corredor havia uma porção de gente, dizendo que ali era um hospital e que havia um bebê em coma na sala que antes era a de sua análise. A porta estava entreaberta e ela viu um bebê com um pijaminha branco, quietinho, deitado na cama. Ao lado, um casal, abraçado, chorava. Na outra cama, estava uma mulher deitada, chorando muito alto e beijando um outro bebê, muito incomodado, que tentava se esquivar de seus beijos.

Tudo estava indo muito bem e ela estava até pensando em ter mais uma sessão, quando um dia, exatamente uma semana depois do sonho da cadeira de rodas e do bebê morto, ela falou, por acaso, de seu apelido, que vinha da palavra "amigo", no masculino. Era um apelido muito carinhoso, do qual ela gostava muito, que surgiu nos tempos de brincadeiras com as irmãs e a prima. Ele se mostrou muito excitado com a "descoberta" deste apelido, como se a tivesse pego em flagrante. Mesmo depois de terminar a sessão, ele continuou a falar, contando do jantar que tinha dado em sua casa e umas mulheres que faziam parte do movimento feminista (a que ele se referira com desprezo como "este movimento seu") haviam se irritado com o fato de ele as ter chamado de "donzelas" e sugerido que fossem servidas primeiro. Ele contava isto parecendo muito irritado, afirmando que essas mulheres estavam confundindo ideologia com desejo (ele sempre dizia que ela tinha experimentado o gozo, mas não o desejo...). Ela estava ouvindo, estupefata, mas respondeu que ela também se sentiria ofendida se alguém a chamasse de donzela, que isto podia até ser um galanteio, mas era também uma atitude machista, de um homem designando o lugar da mulher. E aí ela aproveitou para dizer que a visão que ele tinha do que era ser mulher era muito estereotipada e tradicional, que ela não estava deixando as unhas crescer e gostava muito de sua mão daquele jeito. Eram mãos grandes, de unhas curtas, mas de mulher. Então, ele colocou a mão dele ao lado da dela para comparar. Ela ficou muito perturbada, mas ainda conseguiu dizer que provavelmente a mão dela seria maior do que a dele, isto acontecia com alguns homens, mas, ainda assim, era uma mão de mulher. Outra coisa: 
aquelas sandálias que ele tinha chamado de franciscanas, querendo caracterizá-las como de homem, para ela, eram sandálias de mulher, e muito bonitas. Aí ele disse que não eram aquelas sandálias que os adolescentes haviam dado a ela. A discussão foi se estendendo, como se estivessem num restaurante.

Ela finalmente levantou-se para sair, pegando o pacote de café que havia comprado na cidade. Já que ele havia introduzido o papo, falando em jantar, e já que a discussão estava correndo como se estivessem fora daquela sala, ela se sentiu à vontade para perguntar se ele gostava de café [não devemos esquecer que ela era sensualista, que adorava o cheiro das coisas, sendo café uma das favoritas]. Ele respondeu que gostava sim, que tinha um sítio, e de vez em quando moía o seu próprio café.

Ela saiu de lá mais ou menos nas nuvens. Se, por um lado estava mais preocupada do que nunca com o machismo dele, que havia se revelado gritante, por outro, estava ultra perturbada com a idéia de ele ter contado do jantar na casa dele, do sítio onde se moía café. Quem sabe um dia ela iria jantar no sítio, e depois tomariam o café moído? E a mão que ele havia colocado tão próxima da sua?

Naquela noite, sonhou que haviam trocado de lugares: ele estava deitado no divã e ela estava sentada atrás dele, ouvindo-o falar de seus problemas com o trabalho.

$\mathrm{Na}$ sessão seguinte, ela falou apenas sobre suas preocupações com o machismo dele e não conseguiu falar dos sentimentos perturbadores. Contou a ele como tinha brigado com a escola de natação das crianças, quando havia visto as palavras "Princesinhas" e "Campeões", marcando as portas dos banheiros feminino e masculino, respectivamente. Achava que o "galanteio" dele tinha o mesmo sentido, de discriminação, e que era perigoso. Ele então disse que ia falar "como Abelardo", como homem. Disse que algumas mulheres estavam confundindo as coisas, que viam ideologia onde apenas havia desejo. A Erundina, por exemplo, "aquele bofe de mulher, de bigodes". Mulher não precisa ser desgrenhada para ter o poder. Mulher deve ser bem 
vestida, deve saber mexer as cadeiras para receber o pênis, deve saber ser desejada. [Anteriormente, ela havia lhe falado de sua dificuldade de fazer exercícios na aula de dança por não ter flexibilidade nos quadris.]

Quando ouviu a referência grosseira à Erundina, ela ficou estarrecida. Logo a Erundina! Ela havia se rejubilado no dia em que esta mulher, que contrariava estereótipos que a mulher deve preencher para ser aceita no Brasil - solteira, inteligente, 52 anos, origem humilde - havia sido eleita prefeita da maior cidade da América Latina! Além disso, ele estava usando as mesmas palavras que os representantes do machismo brasileiro haviam usado para descrever a Erundina, coisa que a havia revoltado alguns meses antes.

O sonho, ele interpretou como ela querendo trocar de lugar com a masculinidade dele. Nem por um momento lhe ocorreu que o sonho pudesse estar dizendo da outra troca de lugar - de analista e paciente. Isto é compreensível, pois desde a sessão anterior, ao contar sobre o jantar em sua casa, ele já havia tirado a fantasia de analista, e só sua masculinidade importava agora.

Ela saiu preocupada. Não conseguira falar dos sentimentos perturbadores em relação a ele, e sentira que ele também não a deixara falar. Ele geralmente falava muito, deixando pouco lugar para o silêncio, mas desta vez ele falara mais do que o usual. Parecia muito excitado com a discussão, repetindo que ela estava se preparando para se encontrar com um homem de verdade.

A preocupação dela foi aumentando e à noite, quando lavava o rosto antes de dormir, olhou-se no espelho e gostou muito do rosto que viu. Havia nele uma luz muito bonita que vinha de dentro. Ela se lembrou que ele a havia chamado de cucaracha como forma de estabelecer um contraste entre ela e seu namorado americano, que ele havia debochado da chacarola como ela e sua família carinhosamente chamavam o pequeno sítio que possuíam. E se identificou com a Erundina e com a mulher desgrenhada, de unhas curtas, de sandálias franciscanas. E então compreendeu que ele nunca conseguira ver sua luz e que esta 
corria o risco de ser apagada por ele, por mero descuido. Nesta hora, ela decidiu que ia embora.

No dia seguinte marcou hora com uma psicanalista que seu antigo analista do Rio havia lhe indicado, mas acabou desmarcando. Comprou o livro de conversas de Marguerite Duras com Xavière Gauthier - Boas Falas -, escreveu uma dedicatória para ele, agradecendo "a ajuda até aqui", e entregou a ele assim que se sentou no divã [ela não se deitou nesta sessão], dizendo que aquele era seu último dia ali.

Na realidade, só conseguiu ir embora daí a um mês. Porque não é fácil sair de uma situação de abuso. É uma situação extremamente sedutora, na qual a gente entra sem perceber o perigo, leva muito tempo até se dar conta do que está acontecendo, e, uma vez percebido, não consegue sair logo porque a gente se sente cúmplice. Por que então ela gostava tanto da análise? Por que tinha pedido mais sessões?

A sedução continuou, mesmo depois que ela anunciou que ia embora por causa do que estava acontecendo. Ele admitiu que havia cometido um "erro técnico", isto é, havia agido de uma forma que ele achava que ela iria agüentar, mas ela não agüentava ainda. Quanto ao homem rejeitador, machista, machão, insensivel, que aparecera ali, aquele era um fantasma dela, e não tinha nada a ver com ele. O problema é que ele tinha aparecido como homem, e ela tinha se assustado por causa do seu problema de lidar com homem. Porém, ele achava que o erro não era irreversível e podiam tentar continuar a análise, se ela quisesse. Ela quis, não houve dúvidas. A atitude dele, admitindo o erro havia sido encantadora, e ela manteve a confiança nele. Ela tinha até esperança de que agora a análise deslanchasse de vez.

Houve mais seis encontros, ele nunca mais ofereceu o ursinho e se manteve sério, tomando cuidado com as palavras. Durante este tempo, ela sonhou que ela $e$ o filho eram levados por uma mulher fantasiada, num táxi que parecia carro de circo, para uma belíssima loja de antiguidades e peças raríssimas. Ela entrara numa luta corporal com a mulher, com um sorriso de Cecília 
Meireles, que ficava lhe escapando, dizendo que não havia motivo para brigar com ela, que ela não queria lhe fazer mal. Depois, sonhou que a família tinha se mudado a ela tinha ficado porque estava fazendo análise. Quando chegou para ser atendida, não a atenderam bem, não a reconheceram, e ela ficou inteiramente só. Sonhou também que estava fazendo análise num espaço público, como uma enfermaria, e ia passando de divã em divã, checando se as pessoas eram competentes. Quando se deitou em um divã, percebeu que seus pezinhos eram de criança, gordinhos. Mostrou a ele: "Olha! meus pés são de criança!" Nos quinze dias de férias, em conversa com uma amiga psicanalista, ela finalmente decidiu acabar de vez com a história da Chapeuzinho Vermelho.

Ele the disse que a amiga não podia nunca saber o que estava se passando ali, porque não tinha estado presente. Só quem estava ali podia saber. Disse também que havia várias formas de prender pacientes na análise, mas que não ia fazer isto com ela. E reafirmou que ela estava saindo da análise por causa de seu problema de se relacionar com homens. E disse que queria ser seu amigo, que tinha gostado muito de trabalhar com ela, que ela iria conseguir terminar sua análise sim, que ela já tinha mudado muito. E disse que não cobraria aquela última sessão, mas ela insistiu em pagar. Ela também disse que tinha gostado muito de tudo, que queria saber se podia procurá-lo, caso precisasse, que achava que tinha mudado muito mesmo... Deramse um abraço e se despediram.

Alguns dias depois desta despedida tão cordial, ela começou a se sentir muito mal, e aos poucos começou a entender que a história do psicanalista machista que havia cometido apenas um "erro técnico" era, na realidade - pelo menos a sua realidade - a história da Chapeuzinho Vermelho e do Lobo Mau. Só então ela entendeu o sentido do que tinha sabido todo o tempo: "Eu vou te comer". 
Esta é uma história com um final feliz. Afinal, a Chapeuzinho não deixou que o Lobo a comesse. E nem precisou da ajuda de caçador algum. Ela mesma soube se proteger. Para o Lobo também não foi de todo ruim. Ele acabou ganhando um livro com "boas falas", que, se ler com cuidado, vai poder abrir sua visão sobre o que são as mulheres.

Uma dessas "boas falas" no livro de Marguerite Duras com Xavière Gauthier é apropriada para dar um fechamento na história.

M.D. - Elas esperam. Estão fantasiadas, cabelos arrumados, foram ao cabelereiro, estão com um vestido bonito, de flores.

X.G. - Sim, são o que se chama mulheres femininas! Acreditam que a feminilidade é isso, fazem com que acreditem, elas acreditam que são muito mulheres. $\mathrm{O}$ que elas são? São completamente feitas pelo homem.

M.D. - Mas não têm coragem de falar.

X.G. - Mas lhes disseram: "Mulher não tem que falar... Não se meta em política." Diz-se por exemplo: "São assuntos de homem, coisas de homem". Elas esperam; os maridos vão à guerra, elas esperam; vão ao escritório, elas esperam.

M.D. - Seria bom lembrar o que Michelet disse sobre as feiticeiras. É admirável... ele dizia que, na alta Idade Média, as mulheres ficavam sozinhas nas fazendas, nas florestas, enquanto o senhor estava na guerra... e que se entediavam profundamente em suas fazendas, sozinhas; e que sentiam fome, ele estava nas cruzadas ou na guerra do Senhor, $e$ que foi assim que elas começaram a falar, sozinhas, com as raposas ou com os esquilos, os pássaros, as árvores e que, quando o marido retornava, elas continuavam... os homens as encontraram falando sozinhas na floresta... $e$ as queimaram. Para sustar, barrar a loucura, barrar a palavra feminina.

X.G. - Mas Joana d'Arc ouvia vozes. 


\section{Sandra Azerêdo}

M.D. - A mim, [ela] me fascina. Chamaram a atenção sobretudo para a guerreira de... para a mulher de roupa de homem, pois foi por isso, por isso que a mataram. ...Acho incrível que ele, Carlos VII, tenha obedecido a ela, ele fez o que ela quis a os soldados a seguiram a Orleans. Foi preciso um processo para matá-la. ...Todo um aparelho de Estado, judiciário, institucional. Se não, teria sido um assassinato que o povo não teria admitido, imagino, como o de Giordano Bruno. [Silêncio] Bem, vamos parar por hoje?

X.G. - Vamos, sim. 